\title{
PENSAMENTO MODERNO E NORMALIZAÇÃo DA SOCIEDADE*
}

\author{
José Ternes**
}

\section{RESUMO}

Pretende-se fazer uma breve análise do espaço epistemológico aberto na cultura ocidental, a partir do começo do século XIX, e que mereceu de autores como Gaston Bachelard e Michel Foucault a denominação de pensamento moderno. Um acontecimento somente possível pela ruptura com o Cogito clássico que alimentara pretensões excessivamente universalistas, dogmáticas, reduzindo o conhecimento a uma dimensão meramente extensiva, apenas representação da realidade. A modernidade elimina essa relação de exterioridade entre sujeito e objeto, fazendo do saber um acontecimento de essencial historicidade, em que sujeito e objeto estreitam relações, em que saber, como bem assinala Maturana, é sempre ponto de vista do observador, o que significa relativização, dispersão, temporalização de nossas verdades. Mas a modernidade oferece-nos outra surpresa: o compromisso do sujeito no ato de conhecer significa, também, comprometimento. Observamos, com efeito, um processo de assujeitamento do homem moderno. Os novos saberes vão além da tarefa clássica de representação da realidade. Não se trata apenas de investigar. Urge examinar. $\mathrm{O}$ exame é um procedimento novo na história ocidental. Perigoso, também, pois toma para si o destino dos indivíduos. Conhecer é, hoje, normalizar.

Palavras-chave: sujeito; modernidade; saber; historicidade; patologização; normalização.

Os últimos anos do século XVIII são rompidos por uma descontinuidade simétrica àquela que, no começo do século XVII, cindira o pensamento do Renascimento; então, as grandes figuras circulares onde se encerrava a similitude tinham-se deslocado e aberto para que

\footnotetext{
* Artigo recebido em 6/2/2007 e aprovado em 11/6/2007.

** Doutor em Filosofia pela USO e Professor da Universidade Católica de Goiás (UCG). E-mail: joseternes@hotmail.com
} 
o quadro das identidades pudesse desdobrar-se; e esse quadro agora vai por sua vez desfazer-se, alojando-se o saber num espaço novo. (FoucAult, 1966, p. 229)

Em poucas linhas, Michel Foucault esboça toda a história do pensamento ocidental do século XVI em diante. Três configurações, "quadros" (tableaux), se sucedem, definindo as três grandes epistemes analisadas em As palavras e as coisas. ${ }^{1}$ Não há continuidade entre tais disposições. São camadas, espaços epistemológicos, essencialmente diferentes entre si, e cuja origem, ou explicação, parece escapar às reais possibilidades da Arqueologia (nome dado às histórias dos saberes empreendidas pelo filósofo). O que se pode fazer, talvez, seja expor ou contrapor essas configurações, mostrar a novidade essencial que cada uma significa face à anterior. Cremos, no entanto, que nem isto seja aqui possível. Importa-nos explicitar o "espaço novo" em que o saber moderno se aloja, e qual o alcance desse acontecimento. Para tanto, vamos assinalar, brevemente, o que nos parece indispensável à compreensão da Idade Clássica, pois é esta época que aparece como nosso passado, como nosso anacronismo, aquilo que não mais "se presta ao saber" (Foucault, 1966, p. 68).

A configuração epistemológica da Idade Clássica foi objeto de estudo de muitos historiadores das ciências nas últimas décadas. Uma passagem de La logique du vivant, de F. Jacob, mostra o essencial:

Em menos de um século, os corpos vivos se limpam [...]. Desembaraçam-se de sua camada de analogias, de similitudes e de signos, para aparecer na nudez das linhas e das superfícies determinadas pela visão. Não é mais possível colocar em um mesmo plano a forma de uma planta ou de um animal e as idéias que deles podem ter os viajantes, os historiadores ou os juristas. O que é lido ou ouvido não se iguala mais ao que é visto. $\mathrm{O}$ aspecto dos seres vivos, sua estrutura visível torna-se então objeto de análise e de classificação. (JАCOB, 1970, p. 37)

Para M. Foucault, o saber dos séculos XVII e XVIII somente se torna compreensível em sua estreita relação com a ordem. Matematização, mecanicismo, racionalismo não mereceriam o peso que tiveram nas histórias tradicionais. O que deve ser levado em conta são as exigências incontornáveis da Ordem. Aliás, a própria idéia de Natureza, 
conceito essencial dessa época, somente recebe sentido se relacionada com a de ordenação. A Natureza é natureza se ordenada, se investida de leis, de regularidades. Daí que conhecer nada mais seria do que decifrar a Natureza, expor a sua infinita e imperturbável regularidade. Dar dela um quadro, o mais completo possível. G. Deleuze, ao falar da interpretação foucaultiana da Idade Clássica, assim se expressa:

O que define esse solo, o que constitui esta grande família de enunciados ditos clássicos, funcionalmente, é esta operação de desenvolvimento ao infinito, de formação de continuums, de desdobramentos de quadros: desdobrar, sempre desdobrar - explicar. O que é Deus, senão a explicação universal, o desdobramento supremo? $\mathrm{O}$ desdobramento aparece aqui como um conceito fundamental, o primeiro aspecto de um pensamento operatório que se encarna na formação clássica. (DeleuZe, 1988, p. 134-135)

Talvez encontremos em Diderot, num de seus artigos da Encyclopédie, a expressão bastante fiel dessa compreensão do saber:

Para formar um cabinet d'Histoire naturelle não é suficiente reunir sem escolher, e amontoar sem ordem e sem gosto, todos os objetos da História natural que a gente encontra; é necessário saber distinguir o que merece ser guardado do que é necessário rejeitar e dar a cada coisa uma disposição conveniente. A ordem de um cabinet não pode ser aquela da natureza; a natureza apresenta sempre uma sublime desordem. (DiDERot, 2001, p. 254)

Essa ordem, percebe-se logo, não pode estar a cargo de qualquer indivíduo. É tarefa de uma figura emblemática da Idade Clássica, o naturalista. O Gabinete, efetivamente, é a ciência realizada. Deveria, continua Diderot, gravar "na memória a imagem da natureza" (Diderot, 2001, p. 257). Sua organização é feita, diz d'Aubenton, segundo

a ordem metódica que distribui as coisas que ele compreende em classes, em gêneros e em espécies; assim os animais, os vegetais, e os minerais serão exatamente separados uns dos outros; cada reino terá uma repartição à parte. A mesma ordem subsistirá entre os gêneros e as espécies; colocam-se os indivíduos de uma mesma espécie uns perto dos outros, sem que jamais seja permitido distanciálos. Ver-se-ão as espécies em seus gêneros, e os gêneros em suas classes. (D’Aubenton, apud Diderot, op. cit., p. 257) ${ }^{2}$ 
Percebe-se que tal empreendimento responde às exigências clássicas da visibilidade. A ordem do cabinet é dada ao olhar: "neste gênero de estudo, quanto mais se vê, mais se sabe", diz D'Aubenton (op. cit., p. 259).

Vale a pena insistir no que nos parece mais fundamental. O cabinet d'histoire naturelle tem um sentido preciso na configuração do saber clássico, principalmente no século XVIII. Ao lado dos jardins botânicos, configura o que há de mais adequado a um tipo de conhecimento que é, por excelência, visão. Ambos esses lugares têm por finalidade dar a conhecer a estrutura visível. Traduzem uma disposição epistemológica que marcou o pensamento ocidental durante dois séculos. Saber fora, de Descartes a D'Alembert, antes de tudo, representação. Ora, tal disposição epistemológica encontra sua exaustão na virada para o século XIX. Estamos na época das revoluções científicas modernas, mas, principalmente, de mudanças no modo de ser de toda a cultura ocidental:

mutações que fazem com que de súbito as coisas não sejam mais percebidas, descritas, enunciadas, caracterizadas, classificadas e sabidas do mesmo modo e que, no interstício das palavras ou sob sua aparência, não sejam mais as riquezas, os seres vivos, o discurso que se oferecem ao saber, mas seres radicalmente diferentes. (FouCAULT, 1966, p. 229)

O conhecimento-visão, dado na relação de exterioridade entre sujeito e objeto, ${ }^{3}$ perde, então, força. Não é mais na ordem das razões que a verdade deve ser procurada. Seu espaço adequado deixa de ser a representação. Kant precisaria ser levado a sério: não é por acaso que a Crítica da razão pura começa com uma referência à experiência e ao tempo. Foucault vê, nessa inversão copernicana do pensamento ocidental, a constituição de um novo solo epistemológico. E lhe dá um nome: História. Assim como a Ordem, na Idade Clássica, não era apenas um capricho de uma razão meticulosa, mas o lugar, o único lugar em que os seres poderiam se dar a conhecer, assim também, na virada para o século XIX, a história é mais do que uma entre tantas possibilidades analíticas. Ela se torna o único espaço a partir do qual nossas verdades poderão vir à existência. Torna-se "o incontornável de nosso pensamento" (FoucAult, 1966, p. 231).

Ocupemo-nos, brevemente, com essa disposição geral do saber ocidental moderno definido por Foucault como histórico. Estamos acos- 
tumados a distinguir, desde Marx, entre natureza e cultura. Somente esta, obra do homem, ocuparia um lugar na história. Esqueçamos esta demarcação. Para o arqueólogo, a partir do século XIX, todos os seres se historicizam. Os seres clássicos harborizavam. Os modernos, historicizam, podemos dizer. Vejamos o que isto significa. Interroguemos alguns desses novos objetos, antes impensáveis.

Naissance de la clinique lembra duas perguntas de médico que servem de baliza para dois regimes de verdade. O diálogo entre o médico e o doente até o fim do século XVIII costumava começar com esta pergunta: Qu'avez vous? - Já o médico moderno começa com uma pergunta bem diferente: Où avez vous mal? (Foucault, 1972, p. XIV). Um olhar atento vê logo mudanças muito sérias nessa inversão.

Para a Idade Clássica, o mal ocupava, efetivamente, outro espaço. Não coincidia com o corpo doente. "A coincidência exata do corpo da doença com o corpo do homem doente é um dado histórico e transitório. Seu encontro só é evidente para nós..." (Foucault, 1972, p. 1). A doença clássica era uma espécie natural, dada no quadro sem profundidade da representação. Quando os modernos não mais consideram a doença como espécie, quando a desentificam e lhe dão um caráter apenas adjetivo, quando a percebem como lesão do tecido, e não como hóspede do corpo, opera-se uma das mais significativas revoluções epistemológicas da medicina. É o corpo o lugar da verdade, agora. E este é, de pleno direito, histórico. A verdade da doença será, então, a verdade do corpo doente, um acontecimento da vida do homem. Um acontecimento sempre relacionado com o nascimento e a morte. No caso particular da medicina patológica, mais ostensivamente com a morte: "A noite viva se dissipa na claridade da morte" (Foucault, 1972, p. 149).

A arqueologia dos objetos empíricos de Les mots et les choses oferece-nos conclusões bastante próximas das de Naissance de la clinique. O filósofo investiga o nascimento da vida, do trabalho e da linguagem na passagem para o século XIX. Objetos, cuja existência seria possível somente com profundas modificações no modo de ser do pensamento ocidental. Fora preciso, lemos no começo do Capítulo VIII do livro, que o saber mudasse "de natureza e de forma" (FoucAult, 1966, p. 264). Fora preciso buscar em outro espaço, que não o da representação, as condições de possibilidade desses objetos. Tal espaço, já adiantamos, é a História: Então, diz Foucault, "o valor deixou de ser signo, tornouse um produto" (FouCAULt, 1966, p. 266-7). "A vida não é mais o que se 
pode distinguir, de maneira mais ou menos certa, do mecânico; é aquilo em que se fundam todas as distinções possíveis entre os seres vivos" (Idem, p. 280-281). E, finalmente, "a linguagem se dobra sobre si mesma, adquire sua espessura própria, desenvolve uma história, leis e uma objetividade que só a ela pertencem. Tornou-se um objeto de conhecimento entre tantos outros" (Idem, p. 309).

Os três trechos, é fácil perceber, referem-se a três saberes: a economia política, a biologia e a filologia (ou história das línguas). Seus objetos (trabalho, vida, linguagem) significaram mudanças epistemológicas fundamentais. Eles são, constitutivamente, históricos. Todo valor somente se esclarece referido às suas condições de produção, ao trabalho do homem. Tem sempre uma origem, um lugar de nascimento, mas, ao mesmo tempo, está sempre sob a ameaça da desvalorização, do desaparecimento. Nascimento e morte são, também, condições para o conhecimento dos vivos. Finalmente, a linguagem torna-se objeto separado, assume uma densidade própria. Torna-se acontecimento único, cuja história pode ser escrita. As línguas, também elas, nascem e morrem.

Podemos constatar exemplos similares em outros historiadores, ainda que a partir de critérios diferentes. Bachelard, por exemplo, nos mostra, no campo das ciências matemáticas, mudanças decisivas. Le nouvel esprit scientifique assinala a novidade essencial das ciências modernas. As novas geometrias, a Relatividade einsteiniana, a Teoria dos Quanta, são os exemplos mais instrutivos. Mais do que acumulação de conhecimentos, aconteceram modificações na natureza e na compreensão mesma do conhecer:

como se sabe, não é a propósito da imagem do Mundo, como astronomia geral, que a Relatividade ganhou impulso. Ela nasceu de uma reflexão sobre os conceitos iniciais, de uma colocação em dúvida das idéias evidentes, de um desdobramento funcional das idéias simples. (BACHELARD, 1978, p. 47)

Ao lado de Bachelard e de Foucault, há, sem dúvida, muitos outros historiadores do pensamento ocidental, igualmente notáveis: Prigogine, Geymonat, Cavaillés, Koyré, Maturana, Canguilhem etc. Todos eles, apesar das diferenças, deixam muito claro que nossa modernidade tem uma natureza própria, e não pode ser entendida como o simples aperfeiçoamento de uma história de há muito já preparada. E mais, tal 
natureza diz respeito ao pensamento. As mudanças são, em essência, de ordem conceitual.

As incursões por alguns textos de historiadores do pensamento ocidental permitem, pois, perceber alguns aspectos decisivos de nossa modernidade. Mas permitem também, como bem mostram Ilya Prigogine e Isabelle Stengers, tomar consciência de que nosso tempo nasce do desencantamento das promessas, demasiadamente otimistas, dos séculos XVII e XVIII. Do ponto de vista estritamente epistemológico, podemos dizer, sem dúvida, que a revolução da modernidade tem a ver com a mudança de objeto. Entender nossa época significa perguntar-se acerca da natureza dos novos objetos nascidos ou constituídos a partir dos começos do século XIX.

Vimos, com Foucault, que os novos objetos empíricos são históricos. Pensamos que Bachelard, e muitos outros, mostram o mesmo em outros campos do saber. A nosso ver, a historicização dos objetos, seu deslocamento para fora da pura esfera da representação, constitui o acontecimento mais sério dos últimos séculos da cultura ocidental, tão importante, sem dúvida, quanto o nascimento do Logos (ou da Theoria) na Antiga Grécia ou a revolução galileana no começo do século XVII. Na verdade, o pensamento moderno transgride a própria noção de ciência, ou de verdade científica, que o Ocidente adotara desde Platão. Universalidade, objetividade, pontos de partida absolutamente seguros etc. perdem força agora. A ciência clássica, em especial, se fez a partir do ideal laplaceano de um determinismo universal. O demônio de Laplace, muito mais do que uma possibilidade real, traduz uma possibilidade de princípio, diz Prigogine, a de "observar, num momento determinado, a posição e a velocidade de cada massa constitutiva do Universo, e daí deduzir a evolução universal, tanto na direção do passado como na do futuro" (Prigogine, 1984, p. 59). Ideal somente possível numa relação de exterioridade entre Sujeito e Objeto. Ao se historicizarem, os novos objetos perturbam tal relação. Deixam de ser pura exterioridade. Assumem uma espessura própria. Intensificam-se. Recobram, de alguma forma, interioridade e profundidade. O objeto clássico, dado na representação, não podia ser profundo. As imagens não têm interior. Oferecemnos quadros, ordens dadas ao olhar. Não há como, e não é preciso, ir além da ocularidade: ver, saber. Vimos como procedem os naturalistas, os gramáticos, os economistas. Galileu, mostra Koyré, apresenta-nos um mundo sem "nenhuma alegria" (KoYré, 1973, p. 58). Os habitantes 
desse mundo são da ordem da geometria, e esta, a de Euclides, é plana, seus objetos se dão na superfície. Quando Bichat diz a seus alunos: "abram alguns cadáveres" (cf. FoucAult, 1972, p. 149), faz muito mais do que dar uma instrução de rotina. Essa frase está na base de uma reorganização mais geral do saber. O médico francês é contemporâneo de Cuvier, de Ricardo, de Nietzsche, de Poincaré, de Kant, de Darwin, de Hölderlin. Agora, não se trata mais de dar o quadro (plano) em que os seres podem ser localizados, ou vistos. Agora é preciso que os seres falem. Como na Renascença, assistimos, a partir do século XIX, o retorno da prosa do mundo, ou segundo Foucault, o retorno da linguagem.

Se, no entanto, o saber moderno recobra a alegria perdida, não há motivos para muita festa. Na verdade, o que nos é devolvido, é a finitude. Conhecer, hoje, é ter que se haver com o finito, o condicionado, a história, enfim. É ter que se confrontar, constantemente, com a possibilidade de superação, de envelhecimento, de degeneração do objeto. Mais do que isso, em certos setores da ciência moderna, o objeto é tão precário que somente nos é dado ao saber no movimento mesmo do conhecer:

Pode-se dizer que, durante vinte e cinco anos, Lobatchewsky ocupouse mais em estender sua geometria do que em fundá-la. Igualmente, não se podia fundá-la a não ser estendendo-a. Parece que Lobatchewsky deseja provar o movimento, avançando. (BACHELARD, 1978, p. 29).

Essa discussão também nos coloca diante de um sério impasse. Ao mesmo tempo em que clamamos pelo universal, por fundamentos que nos dêem, novamente, segurança, os historiadores epistemólogos há pouco listados, todos eles, reconhecem que, infelizmente, não há mais fundamentos. Que o saber não está inscrito, a priori, na Natureza, ou em outro ponto fixo, bastando alguma competência para a ele aceder. Ele é nossa invenção, depende, como bem mostra Humberto Maturana, de nosso ponto de vista: "tudo é dito por um observador" (MATURANA, 1997, p. 53). A modernidade, já assinalamos, elide a tradicional separação entre sujeito e objeto. Se ainda podemos utilizar hoje tais termos, precisamos sempre estar atentos ao fato de que tanto um quanto outro são relativos, se constituem mutuamente. Bachelard arrisca, inclusive, um novo termo: projeto. Mas a palavra não é o mais importante. Importa assinalar que a moderna configuração do saber coloca algumas lições, ou, talvez, algumas exigências para aqueles que, de alguma forma, com ele se ocupam. E quem, aqui, não se ocupa com o saber? Se assim é, talvez se 
recomende maior atenção para a natureza essencialmente aberta do pensamento moderno. Muitos setores da cultura de nossos dias ainda respiram ares epistemológicos francamente iluministas.

$\mathrm{Na}$ verdade, reconhecemos uma estreita relação entre uma certa compreensão do conhecimento e as nossas práticas como profissionais. Raramente nos damos conta disso. Estão, quase sempre, muito ocupados. Ou então, dizem, há coisas mais importantes, mais úteis, a fazer. Ler Bachelard, Koyré, Canguilhem, Maturana, Foucault (especialmente o arqueólogo, mais difícil), Prigogine, e muitos outros, pode parecer perda de tempo. O que, no entanto, investigam estes filósofos? Ocupam-se com a natureza do pensamento, o moderno, em especial. E o que fazemos nós, advogados, psicólogos, historiadores, economistas? Ocupamo-nos, diuturnamente, com o saber. Com matemática, física, língua-pátria, história, teologia, sociologia, psicologia, filosofia, leis, doenças etc. Realizamos, ou pretendemos realizar, pensamentos modernos, em última instância. Ninguém ousaria ser anacrônico! Não estamos, pois, tão distantes! Antes de buscar lições de fora (e as encontramos, de todos os matizes), talvez o próprio pensamento moderno nos coloque algumas exigências. E a primeira de todas: não é mais possível ser clássico (no sentido há pouco colocado).

A inversão epistemológica moderna requer, a nosso ver, outra relação com o saber. Não é mais possível, ou desejável, ser apenas cartesiano. Uma relação de exterioridade seria, hoje, o empobrecimento do saber. Este não é mais, como queria Diderot, simples objeto de instrução. Instruir pode bem ser tarefa primeira dos povos civilizados. ${ }^{4}$ O Relatório Delors o mostra bem. Mas, instruir, instruir-se, é muito pouco.

Saber, hoje, coloca exigências maiores do que a instrução. E tais exigências nascem do modo de ser, da natureza mesma do saber moderno. Saber-invenção, antes que saber-espetáculo. É compreensível, e perfeitamente aceitável, que D'Aubenton atribua ao Cabinet d'histoire naturelle du roy a função precípua da ocularidade. Era preciso que o visitante tivesse uma visão clara e distinta da ordem dos seres da Natureza. Saber era, antes de tudo, ver para o clássico. E instruir, instruirse, era possibilitar ver melhor. Ora, um biólogo que, em nossos dias, reduzisse seu saber ao visível, que se desse por satisfeito com um conhecimento dado ao olhar, que se contentasse em dar visibilidade a seus objetos, seria uma figura, no mínimo, anacrônica. Nossa modernidade nasce quando o princípio da visibilidade perde força, quando o 
visível e o invisível se reaproximam. Quando, enfim, o invisível assume privilégios epistemológicos semelhantes aos da visão. Um físico contemporâneo que limitasse a dar instruções sobre o que é visível seria bastante estranho. Os objetos da física moderna, da microfísica, por exemplo, não se dispõem ao olhar. Mais do que coisas observáveis e mensuráveis, são pensamentos, "sombras de um número" (BACHELARD, 1978, p. 86). Mais do que coisas a ver, são seres a pensar.

Se o profissional tem algo a aprender investigando o pensamento moderno, talvez seja essa inversão no modo de saber. Na modernidade, ordem e desordem, visível e invisível, luz e penumbra, pensado e impensado, pertencem a um mesmo movimento. $E$ isto não tem nada com irracionalidade ou com ceticismo. Ao contrário, é do lado da razão, da formação intelectual, que está a possibilidade de sucesso. O homem moderno, mais do que adquirir conhecimentos, precisa, constantemente, recriá-los. Um projeto de Enciclopédia, ou, como vemos em Condorcet, um Esboço dos progressos do espírito humano, perderiam, hoje, muito de seu sentido. Pelo menos, não podem mais ser o primeiro e único objetivo do homem culto. A modernidade nos obriga, sem dúvida, a rever a própria idéia de cultura, de homem preparado para a vida.

De uma coisa temos certeza: não é mais possível imaginar fundamentos para nossos saberes, pois, simplesmente, todos os fundamentos entraram em ruína há, pelo menos, dois séculos. Encontramo-nos, no momento, enredados em mil polêmicas, envolvendo temas como modernidade, pós-modernidade, estruturalismo, pósestruturalismo, culturalismo, conhecimento em rede etc. Movimentos de superficie, diria Foucault. Provavelmente todas essas iniciativas pertencem a um solo comum, a uma configuração mais ampla do saber de nosso tempo, e que se caracteriza, justamente, pela dispersão. Em todo caso, a configuração epistemológica contemporânea não nos parece autorizar bases muito seguras. Os debates atuais se desenvolvem, certamente, a partir de referenciais outros que os estritamente epistemológicos. E não cabe, aqui, a pergunta acerca de sua legitimidade. Pensamos, no entanto, que há questões que emergem do interior do próprio pensamento atual, e que têm seu peso. Os epistemólogos insistem, mesmo, que o que deve ser levado em conta, antes de tudo, é o saber, que nossa relação é com o saber, antes de tudo, e que tudo o mais deveria ser pensado em função deste. Mas, se o saber moderno é tão frágil, tão relativo, tão pouco seguro, por que com ele nos ocupar? Não poderíamos 
nos colocar a serviço de outras instâncias, mais urgentes talvez, do que o saber? Por exemplo, o mercado, a sociedade, o homem? Uma passagem de As palavras e as coisas é suficiente para nos devolver a lucidez:

Esse duplo movimento próprio ao cogito moderno explica porque nele o Eu penso não conduz à evidência do $E u$ sou; de fato, assim que o Eu penso se mostrou imbricado em toda uma espessura onde ele está quase presente, que ele anima mas à maneira ambígua de uma vigília sonolenta, não é mais possível fazer dele decorrer a afirmação de que Eu sou: posso eu dizer, com efeito, que sou essa linguagem que falo e na qual meu pensamento desliza ao ponto de nela encontrar o sistema de todas as suas possibilidades próprias, mas que, no entanto, só existe sob o peso de sedimentações que ele jamais será capaz de atualizar inteiramente? Posso eu dizer que sou este trabalho que faço com minhas mãos, mas que me escapa, não somente quando o concluo, mas antes mesmo de o haver encetado? Posso eu dizer que sou essa vida que sinto no fundo de mim, mas que me envolve tanto pelo tempo formidável que ela impulsiona consigo e que me eleva por um instante sobre sua crista, quanto pelo tempo iminente que me prescreve minha morte? Posso dizer tanto que sou quanto que não sou tudo isso; o cogito não conduz a uma afirmação do ser, mas abre justamente para toda uma série de interrogações onde o ser está em questão: que é preciso eu ser, eu que penso e que sou meu pensamento, para que eu seja o que não penso, para que meu pensamento seja o que não sou? Que é, pois, esse ser que cintila e, por assim dizer, tremeluz na abertura do cogito, mas que não é dado soberanamente nele e por ele? Qual é, pois, a relação e a difícil interdependência entre o ser e o pensamento? Que é o ser do homem, e como pode ocorrer que esse ser, que se poderia tão facilmente caracterizar pelo fato de que 'ele tem pensamento', e que talvez seja o único a possuí-lo, tenha uma relação indelével e fundamental com o impensado? (Foucault, 1966, p. 335-336).

Foucault, com sua dose de ironia, nos oferece o tom de tudo o que dissemos. O tempo seguro do Cogito parece ter encontrado seu esgotamento. Bases firmes, pilares, monumentos, abóbadas, torres, palácios (da natureza, ou de nosso narcisismo) são sempre possíveis, mas como reabilitação de uma metafísica elidida ou, pelo menos, contestada há bastante tempo. 
Está na hora, no entanto, de nos ocuparmos brevemente com outro aspecto do pensamento moderno e que não é, em tese, da estrita ordem do saber, embora, a meu ver, não se encontre fora dela. Talvez não seja tão evidente nas ciências matemáticas, como a física e a química. Mas em outros campos epistemológicos, como os da Biologia, Medicina, Psicanálise, Direito, Ciências Humanas, mal pode ser disfarçado. Refirome ao caráter essencialmente normativo, normalizador das ciências modernas.

Tomemos esta passagem, um pouco longa, de Vigiar e punir, que fala do nascimento da medicina moderna no final do século XVIII:

Uma das condições essenciais para a liberação epistemológica da medicina no fim do século XVIII foi a organização do hospital como aparelho de examinar. O ritual da visita é uma de suas formas mais evidentes. No século XVII, o médico, vindo de fora, juntava à sua inspeção vários outros controles - religiosos, administrativos; não participava absolutamente da gestão cotidiana do hospital. Pouco a pouco a visita tornou-se mais regular, mais rigorosa, principalmente mais extensa: ocupou uma parte cada vez mais importante do funcionamento hospitalar. Em 1661, o médico do Hotel-Dieu de Paris era encarregado de uma visita por dia; em 1687, um médico expectante devia examinar, à tarde, certos doentes mais graves. Os regulamentos do século XVIII determinam os horários da visita, e sua duração (duas horas no mínimo); insistem para que um rodízio permita que seja realizado todos os dias 'inclusive domingo de Páscoa'; enfim em 1771 institui-se um médico residente, encarregado de 'prestar todos os serviços de seu estado, tanto de noite como de dia, nos intervalos entre uma visita e outra de um médico de fora' (Registres de délibérations du bureau de l'Hôtel-Dieu). A inspeção de antigamente, descontínua e rápida, se transforma em uma observação regular que coloca o doente em uma situação de exame quase perpétuo. (FouCAULT, M. 1977, p. 165)

Logo a seguir, Foucault nos oferece ainda dois exemplos: a escola e o Exército. A escola será "cada vez menos (o local) daquelas justas em que os alunos defrontavam forças e cada vez mais (o espaço) de uma comparação perpétua de cada um com todos, que permite ao mesmo tempo medir e sancionar" (Idem, p. 166). Quanto ao exército, tornou-se clássica a distinção entre o soldado do século XVII e o recruta do século 
XVIII, descrita pelo filósofo no começo da Terceira Parte do livro: aquele, diz Foucault,

é antes de tudo alguém que se reconhece de longe; que leva os sinais naturais de seu vigor e coragem, as marcas também de seu orgulho, seu corpo é o brasão de sua força e de sua valentia; e se é verdade que deve aprender aos poucos o ofício das armas - essencialmente lutando - as manobras como a marcha, as atitudes como o porte da cabeça se originam, em boa parte, de uma retórica corporal da honra. (Idem, 125).

Já o soldado moderno

tornou-se algo que se fabrica; de uma massa informe, de um corpo inapto, fez-se a máquina de que se precisa; corrigiram-se aos poucos as posturas, lentamente uma coação calculada percorre cada parte do corpo, se assenhoreia dele, dobra o conjunto, torna-o perpetuamente disponível, e se prolonga em silêncio, no automatismo dos hábitos; em resumo, foi "expulso o camponês" e the foi dada a "fisionomia de soldado". (loc. cit.)

Pudemos ver, anteriormente, que a clínica moderna torna-se possível quando se abandona a representação e o olhar do médico se volta para o doente: "Onde lhe dói?" O mesmo movimento fora observado em relação ao nascimento de outros objetos: a vida, o trabalho, a linguagem, o louco, agora doente mental. É possível, sem dúvida, descrever esse movimento como um acontecimento "na ordem do saber". Foi o que Foucault fez em seus primeiros livros, em sua Arqueologia. Acredito, no entanto, que já paira aí a suspeita de que há algo mais do que o desinteressado saber. O retorno ao leito do doente, a multiplicação das visitas do médico ao hospital significam, sem dúvida, um novo olhar. Há os que vêem nisso um renascer do humanismo, a valorização, enfim, do outro. O Foucault genealogista constata que o novo médico, em sua investigação, faz mais do que um simples inquérito. Faz algo absolutamente diferente: examina. O novo recruta, "massa informe", "corpo inapto", também ele não está mais livre para ser o que a sua natureza poderia, talvez, prenunciar. Até nossos dias, o recruta não apenas passa por uma inspeção inicial, mas será diuturnamente examinado. Na escola, observa-se o mesmo acontecimento: "a prova com que terminava um aprendizado na tradição corporativa validava uma aptidão adquirida - a 'obra-prima' autenticava uma transmissão de saber já feita" (FouCAult, 
1977, p. 166). A pedagogia moderna não se contenta com a manifestação do aprendido. Não basta provar. $\mathrm{O}$ aprendiz moderno entra num processo nunca acabado de exame.

Por que, no entanto, em nossa modernidade, é preciso examinar? Por que os novos objetos (o doente, o soldado, o presidiário, o aluno, o operário etc.) não são apenas pesquisados e explicados? Por que decifrar, ou simplesmente descrever, como fora propósito da ciência clássica, não basta? Que saberes são esses que, ao produzir um saber sobre seus objetos, os modificam também? Dão-lhes nova fisionomia? Finaliza-o? Que saberes são esses que, sem alarde, devolvem à cultura ocidental uma figura elidida na aurora da idade científica, a causa final, ainda que com novas feições? Há muitas justificativas: uma nova consciência do indivíduo, a valorização do humano, o interesse social, ético, religioso etc. Tudo isso, sem dúvida, pode estar presente. Mas também não é novidade. Sempre se procurou dar à verdade garantias para além da pura cientificidade. Sempre se utilizaram argumentos ad hominem. $\mathrm{Na}$ modernidade, porém, assistimos a um paradoxo: nas novas ciências, mesmo as denominadas humanas, o homem está ausente. O médico não visita um homem. Exerce uma função que individualiza, assujeita, objetiva, examina, elabora um saber. Da mesma forma, a nova escola talvez não seja o lugar de uma relação de liberdade e amizade entre mestre e discípulo. "O exame não se contenta em sancionar um aprendizado; é um de seus fatores permanentes: sustenta-o segundo um ritual de poder constantemente renovado. $\mathrm{O}$ exame permite ao mestre, ao mesmo tempo em que transmite um saber, levantar um campo de conhecimentos sobre seus alunos" (Foucault, 1977, p. 166). O mesmo se pode afirmar do soldado, do operário, do funcionário público (agora chamado servidor), do presidiário (estranhamente denominado reeducando). Não se sabe simplesmente, não se instrui apenas. Desde o fim do século XVIII, o saber perde sua inocência. Saber é também normalizar. Saber-exame, saber-normalização, saber-poder.

A norma não é, evidentemente, uma invenção da modernidade. Curiosamente, sua tematização se faz primeiro num campo nada normativo: a mecânica, já no século XVII. O termo privilegiado era regulação. Para a Idade Clássica, como vimos no começo, o mundo configura uma ordem rígida, com leis universais a que todos os corpos necessariamente obedecem. Não era de se estranhar que, breve, se colocaria a questão acerca da própria natureza da regulação. Haveria 
um regulador externo, como professava a maior parte dos teólogos, ou se poderia dispensar Deus, uma vez dado o mundo, e admitir um princípio interno de conservação, como acontece, por exemplo, com o animalmáquina de Descartes. Essa discussão, segundo Canguilhem, permaneceu, até a segunda metade do século XVIII, nos limites da mecânica. Somente no século XIX a noção de regulação ganhará cidadania biológica. E somente mais tarde ainda, já no ocaso do século, esse conceito encontrará espaço no discurso das ciências sociais. Não estamos mais diante do funcionamento regular de um relógio, mas da vida e da sociedade, produzindo suas regras de autoconservação e expansão. Em $O$ normal e o patológico, obra mais importante de Canguilhem, lemos que a própria noção de norma sofreu, na modernidade, uma inflexão importante. Enquanto em sua origem grega (nomos) e latina (norma) prevalecia o sentido de lei, de regra, os modernos procederam a um deslocamento. E isto se pode observar, por exemplo, no Vocabulaire technique et critique de la philosophie, de Lalande. Segundo este dicionário, lembra Canguilhem, "é normal, etimologicamente - já que norma significa esquadro - aquilo que não se inclina nem para a esquerda nem para a direita, portanto o que se conserva num justo meio-termo; daí derivam dois sentidos: é normal aquilo que é como deve ser; e é normal, no sentido mais usual da palavra, o que se encontra na maior parte dos casos de uma espécie determinada ou o que constitui a média ou o módulo de uma característica mensurável" (CANGUILHEM, 1982, p. 95). Ora, parece que a nossa sociedade aprofundou a confusão entre a norma como o regular e juridicamente estabelecido, o que deve ser, e a norma como o padrão estatisticamente médio, o que se parece com todos. Mais ainda, confere maior peso à segunda acepção.

Assim, a crescente individuação que se observa na sociedade moderna inverte os ideais revolucionários do liberalismo clássico. Ainda tem sentido falar-se em liberdade, igualdade, fraternidade? - Todos aqueles conceitos sofreram uma inflexão. Os ideais iluministas nascem de uma tensão entre o já estabelecido e um mundo projetado ou sonhado. Os sujeitos que ora emergem pouco guardam daquela tensão. Agora não é suficiente ser sujeito. Melhor, ser sujeito é outra coisa: é ser normal. Ou melhor, o sujeito de que uma vasta literatura não pára de falar, é uma ficção. No lugar do sujeito, o assujeitamento, o seqüestro, não somente do corpo, mas da alma. 
Enquanto os juristas procuravam no pacto um modelo primitivo para a construção ou reconstrução do corpo social, os militares e com eles os técnicos da disciplina elaboravam processos para a coerção individual e coletiva dos corpos. (FouCAult, 1977, p. 152).

O pacto, pelo menos em tese, supõe a decisão de um sujeito, ou dos sujeitos, ainda que seja para delegar a outro o seu poder. A disciplina, fenômeno intrínseco à modernidade, tira do homem a possibilidade mesma de utopia. No capítulo denominado "Corpos dóceis", em Vigiar e punir, Foucault dá a dimensão desse acontecimento:

A disciplina fabrica, assim, corpos submissos e exercitados, corpos dóceis. A disciplina aumenta as forças do corpo (em termos econômicos de utilidade) e diminui essas mesmas forças (em termos políticos de obediência). Em uma palavra: ela dissocia o poder do corpo; faz dele por um lado uma aptidão, uma capacidade que ela procura aumentar; e inverte por outro lado a energia, a potência que poderia resultar disso, e faz dela uma relação de sujeição estrita. Se a exploração econômica separa a força e o produto do trabalho, digamos que a coerção disciplinar estabelece no corpo o elo coercitivo entre uma aptidão aumentada e uma dominação acentuada. (FouCAULT, 1977, p. 127)

É fundamental observar que esse processo de produção de indivíduos economicamente eficientes e politicamente dóceis tem um lugar determinado de desencadeamento e também não seria contido por uma decisão do exterior. A normalização, lembra Márcio A. Fonseca, em seu livro Michel Foucault e o direito, é imanente ao saber moderno. O biólogo não é responsável pela norma, é seu objeto, a vida, que a impõe. As ciências da sociedade certamente buscaram aí as lições primeiras para seu ofício. Da mesma forma que os biólogos, os cientistas sociais também não decidem sobre a normatividade de seus saberes. Ao contrário, o normal e o patológico, antes que efeitos, são condição de possibilidade da sociologia, da psicologia, da pedagogia, do direito, da psicanálise, da medicina etc.

Essa constatação permite, no entanto, mais de uma interpretação. Canguilhem, por exemplo, se confessa otimista. No primeiro capítulo de Nouvel réflexions, "Du social au vital", distingue-se o normal social do normal social, reservando para a capacidade de construir uma normatividade que não necessariamente significaria submissão. 
Tandis que l'exigence des normes est interne à l'organisme, la normalisation à l'oeuvre dans le social repose sur um choix et une décision extérieurs à l'objet normalisé (NP, 176). La nécessité vital de la régulation normative 'immanente' (NP, 176) à l'objet normé disparaît au profite de l'arbitraire social de la décision normative. Une société se construit autour des normes arbitraires e transcendentes aux objets normés. (Le Blanc, 1998, p. 81)

Já em Michel Foucault, a crescente normalização das sociedades contemporâneas, a partir dos saberes emergentes na virada para o século XIX, é motivo de profunda preocupação. Numa sociedade normativa apaga-se qualquer possibilidade de oposição, de diferença. Os revolucionários clássicos eram possíveis porque conseguiam trabalhar com a idéia de uma situação outra que a presente. A norma não permite isso. $\mathrm{E}$ o próprio anormal perde seu poder de alteridade. "O anormal está na norma”, observa F. Ewald (1993, p. 87). Daí que, observamos em Foucault, não há diferença substancial entre o condenado e o cidadão. Ambos encontram-se num mesmo regime. A diferença é de intensidade. Daí, também, o isomorfismo entre as diversas instituições. "A partir do momento em que as disciplinas se tornam normativas, continua Ewald, as instituições se tornam isomorfas umas às outras. A partir do momento em que a sociedade se torna normativa, as instituições - exército, escola, oficina, prisão - tornam-se redundantes umas das outras" (Idem Ibidem). Numa sociedade assim, onde toda a oposição, a polêmica, é suprimida, onde vige um único padrão, a uniformidade plana daquela figura já denunciada por Heidegger em Ser e tempo de o impessoal (“das Man”), aí o desvio, a própria transgressão se torna impensável.

Diria mais, nas sociedades normatizadas atuais, algo como filosofia e ética perde muito de seu sentido. Esses discursos são sempre singulares, nascem da experiência de um pensamento capaz de, como lemos em $O$ uso dos prazeres, afastar-se de si mesmo. No entanto, a normalização segue o caminho inverso, fabrica, como vimos, seus sujeitos. E os fabrica em série. A normalização homogeneíza. A norma, ao contrário da prova, não privilegia os melhores, mas a média. Politicamente, a mediocridade. Daí o pouco entusiasmo de Foucault com os rumos de nossa modernidade. Assim como não mais tem sentido um projeto epistemológico universal e integrador, também não há mais espaço para uma sociedade nos moldes dos sonhos dos iluministas. Paradoxalmente, os espaços insinuados pelo 
filósofo são raros, marginais. Espaços-fuga, na expressão de Deleuze. Espaços-infames.

Em "A vida dos homens infames", Foucault distingue dois tipos de infâmia. Há uma falsa infâmia, diz ele,

aquela de que se beneficiam aqueles homens apavorantes, ou escandalosos, que foram Gil de Rais, Guillery ou Cartouche, Sade e Lacenaire. Aparentemente infames devido às lembranças abomináveis que deixaram, dos delitos que se lhes atribui, do horror respeitoso que inspiraram, são com efeito homens de lenda (légende) gloriosa, mesmo que as razões desse renome sejam o inverso daquelas que fizeram ou deveriam fazer a grandeza dos homens. Sua infâmia não é senão uma modalidade do universal fama ${ }^{6}$

E há uma outra infâmia, aquela dos que seguiram caminhos desconhecidos, tortuosos, às margens ou às sombras da sociedade. "Esses", diz Foucault, "são infames no sentido mais rigoroso; não existem senão através de algumas palavras terríveis que foram destinadas a tornálos indignos, para sempre, da memória dos homens" (sic). O filósofo começa o texto transcrevendo dois registros, breves indicações do começo do século XVIII, e que me permito copiar aqui:

Mathurin Milan, mis à l'hôpital de Charenton le 31 août 1007: "Sa folie a toujours été de se cacher à sa famille, de mener à la campagne une vie obscure, d'avoir des procès, de prêter à usure et a fonds perdu, de promener son pauvre esprit dans des routes inconnues, et de se croire capable des plus grans emplois."

Jean Antoine Touzard, mis au château de Bicêtre le 21 avril 1007: "Récollet apostat, séditieux, capable des plus grands crimes, sodomite, athée si l'on peut être; c'est un véritable monstre d'abomination qu'il y aurait moins d'inconvénient que de lesser libre." "

O trabalho de Foucault sobre esse infames é bastante conhecido. Basta ler Vigiar e punir, o Dossier Rivière ou textos menores de sua genealogia do poder. Não gostaria de insistir nessas notícias (nouvelles) do Século das Luzes. Minha intenção é acrescentar à classificação de Foucault uma terceira infâmia. Esta, própria de nosso tempo. Os mais apressados a chamariam de pós-moderna. Os novos infames não habitam a cidade moderna. Não são dóceis, nem eficientes. Seus espaços são 
outros: a arte, a filosofia, a literatura, a amizade também. Espaços não integrados, puro exterior.

Este espaço neutro é o que caracteriza nos nossos dias a ficção ocidental (e esta é a razão porque já não é nem uma mitologia nem uma retórica). Sendo assim, aquilo que faz com que seja tão necessário pensar esta ficção - quando antigamente do que se tratava era de pensar a verdade - é que o eu falo funciona como o revés do eu penso. Este conduzia com efeito à certeza indubitável do Eu e de sua existência; aquele, pelo contrário, afasta, dispersa, apaga esta existência e não conserva dela mais do que sua citação vazia. $O$ pensamento do pensamento, toda uma tradição todavia mais antiga do que a filosofia, nos ensinou que nos conduzia à interiorização mais profunda. A palavra da palavra nos conduz pela literatura, mas talvez também por outros caminhos, a esse exterior de onde desaparece o sujeito do qual se fala. Sem dúvida é por esta razão pela qual a razão ocidental não decidiu durante tanto tempo em pensar o ser da linguagem: como se pressentira o perigo que faria correr a evidência do existo a experiência nua da linguagem. (Foucault, 1986, p. 14)

\section{NOTAS}

1. Histoire de la folie e Naissance de la clinique trazem os mesmos recortes.

2. Na verdade, o texto de Diderot sobre o Cabinet aparece, na Encyclopédie, como "Suplemento" ao de D'Aubenton.

3. "No conhecimento há apenas duas coisas a considerar, a saber: Nós que conhecemos e os objetos a conhecer" (Descartes, 1977, p. 66, Regra XII).

4. Diderot começa seu Plano de uma Universidade ou de uma Educação Pública em todas as Ciências, falando do valor da instrução. "Instruir uma nação é..." (Diderot, 2000, p. 262).

5. Enquanto a exigência de normas é interna ao organismo, a normalização em processo no social depende de uma escolha e de uma decisão exteriores ao objeto normalizado (NP, 176). A necessidade vital da regulação normativa 'imanente' (NP, 176) ao objeto regulado desaparece em proveito do arbitrário social da decisão normativa. Uma sociedade se constrói no espaço de normas arbitrárias e transcendentes aos objetos regulados" (Le Blanc, 1998, p. 81).

6. Foucault, M. "La vie des hommes infâmes. Paris: Dits et écrits, 1994, v. III, p. 243. 
7. Mathurin Milan, internado no hospital de Charenton a 31 de agosto de 1707: "Sua loucura sempre foi a de se esconder em sua família, de levar na campanha uma vida obscura, de ter processos, emprestar a juros ('prêter à usure') e a fundo perdido, de passear seu espirito por vias desconhecidas, $e$ de se acreditar capaz das maiores façanhas."

Jean Antoine Touzard, internado no castelo de Bicêtre a 21 de abril de 1707: "Teimoso apóstata, sedicioso, capaz dos maiores crimes, sodomita, ateu se se pode sê-lo; é um verdadeiro monstro de abominação que seria menos inconveniente reprimir do que deixar livre" (Op. cit., 237).

\section{REFERÊNCIAS}

BACHELARD, G. L'engagement rationaliste. Paris: PUF, 1972.

. La flamme d'une chandelle. Paris: PUF, 1961.

. La formation de l'esprit scientifique. Paris: Vrin, 1972.

Le nouvel esprit scientifique. Paris: PUF, 1978.

. La flamme d'une chandelle. Paris: PUF, 1961.

La formation de l'esprit scientifique. Paris: Vrin, 1972.

. Le nouvel esprit scientifique. Paris: PUF, 1978.

CANGUILHEM, G. O normal e o patológico. Rio de Janeiro: Forense Universitária, 1982.

EWALD, F. Foucault: a norma e o direito. Lisboa: Vega, 1993.

DELEUZE, G. Foucault. São Paulo: Brasiliense, 1988.

DESCARTES, R. Regras para a direção do espírito. Lisboa: Estampa, 1972.

DIDEROT, D. Choix d'articles de l'Encyclopédie. Paris: Ed. du CTHS, 2001. Obras I e II. São Paulo: Perspectiva, 2001.

FOUCAULT, M. Dits et écrits. Paris: Gallimard, 1994. . Histoire de la folie. Paris: Gallimard, 1972. . Les mots et les choses. Paris: Gallimard, 1966. . O nascimento da clínica. Rio de Janeiro:Forense Universitária,1977. . La pensée du dehors. Paris: Fata Morgana, 1986. . A verdade e as formas jurídicas. Rio de Janeiro: Nau, 1996.

. Vigiar e punir (VP). Petrópolis: Vozes, 1977.

HEIDEGGER, M. Ser e tempo. Petrópolis: Vozes, 1988. 
HEIDEGGER, M. Introdução à metafísica. Rio de Janeiro: Tempo Brasileiro, 1969.

KOYRÉ, Alexandre. Études d'histoire de la pensée scientifique. Paris: Gallimard, 1973.

LE BLANC, G. Canguilhem et les normes. Paris: PUF, 1998.

MATURANA, H. A ontologia da realidade. Belo Horizonte: UFMG, 1997.

PRIGOGINE, I. \& STENGERS, I. A nova aliança. Brasília: UNB, 1984.

TERNES, J. Michel Foucault e a idade do homem. Goiânia: Cegraf/UCG, 1998. 
